\title{
Melanotropin Receptors Demonstrated In Situ in Human Melanoma
}

\author{
Jeffrey B. Tatro, ${ }^{\star}$ Michael Atkins, ${ }^{\ddagger}$ James W. Mier, ${ }^{\text {S Sverrir Hardarson, }}$ " Hubert Wolfe, \\ Thomas Smith," Margaret L. Entwistle," and Seymour Reichlin* \\ Divisions of ${ }^{*}$ Endocrinology and ${ }^{\ddagger}$ Hematology-Oncology, Department of Medicine, and Departments of ${ }^{\S}$ Pathology and $"$ Surgical \\ Oncology, New England Medical Center and Tufts University School of Medicine, Boston, Massachusetts 02111
}

\begin{abstract}
Although some cultured human melanoma cell lines are responsive to melanotropins (melanocyte-stimulating hormones [MSH]), the prevalence and tissue distribution of MSH receptors in melanoma are unknown. We report here the use of an in situ binding technique to demonstrate specific MSH receptors in surgical specimens of human melanoma. The distribution and binding properties of specific MSH binding sites were determined by autoradiography and image analysis after incubation of frozen tumor tissue sections with a biologically active, radiolabeled analogue of alpha-MSH, $\left[{ }^{125} \mathrm{I}\right]$ iodo-Nle ${ }^{4}$, D-Phe ${ }^{7}-$ alpha-MSH ([125I]NDP-MSH). In melanoma specimens from 11 patients, 3 showed high levels of specific binding, 5 showed low levels, and in 3 patients specific binding of [ [ ${ }^{125}$ I]NDPMSH was not detectable. Specific MSH binding sites were present in melanoma cells, but not in adjacent connective or inflammatory tissues. Melanotropins, including alpha-MSH, NDP-MSH, and ACTH, inhibited [ [25 I]NDP-MSH binding in a concentration-dependent manner, whereas unrelated peptides (somatostatin and substance $P$ ) did not. The apparent affinity of alpha-MSH for this binding site was in the nanomolar range $\left(E_{50}=2 \times 10^{-9} \mathrm{M}\right.$ for inhibition of [ ${ }^{125}$ I]NDP-MSH binding in situ), similar to that recently described for the murine melanoma receptor. In one patient, analysis of multiple intratumor samples and tumors excised on three separate occasions revealed high levels of specific MSH binding in all samples. These results suggest that endogenous melanotropins may modulate the activities of human melanoma cells in vivo. ( $J$. Clin. Invest. 1990. 85:1825-1832.) adrenocorticotropic hormone • melanocyte-stimulating hormone • autoradiography • radioligand binding $\bullet$ image analysis
\end{abstract}

\section{Introduction}

Since the discovery that mouse melanoma cell activities are influenced by melanotropins (melanocyte-stimulating hormones $\left.[\mathrm{MSH}]^{1}\right)(1)$, much interest has been focused on the

This work was presented in part at the Annual Meeting of the Endocrine Society, June 1989, in Seattle, WA.

Address reprint requests to Dr. Jeffrey B. Tatro, Endocrinology Division, Box 268, New England Medical Center Hospitals, 750 Washington Street, Boston, MA 02111.

Received for publication 20 November 1989 and in revised form 6 February 1990

1. Abbreviations used in this paper: $\mathrm{MSH}$, melanocyte-stimulating hormone; NDP-MSH, Nle ${ }^{4}$, D-Phe ${ }^{7}$-alpha-MSH.

J. Clin. Invest.

(c) The American Society for Clinical Investigation, Inc.

$0021-9738 / 90 / 06 / 1825 / 08 \quad \$ 2.00$

Volume 85, June 1990, 1825-1832 biological actions and potential clinical value of MSH in human melanoma. Several treatment strategies are currently being developed that aim to exploit the interaction of alphaMSH with its receptors on melanoma cells. These agents are designed to kill the cells either directly, using MSH-toxin hybrid molecules $(2,3)$, or indirectly, by targeting the cells for $T$ cell-mediated destruction using MSH (anti-CD3 receptor) conjugates (4). The clinical potential of these approaches is critically dependent on the presence of functional alpha-MSH receptors on human melanoma cells in vivo. However, while animal melanoma cell lines have long been known to respond to MSH (1) and have recently been shown to express MSH receptors in vitro (5-7) and in situ (5), the frequency with which MSH receptors are expressed in human melanomas is unknown.

Metabolic effects of MSH have been detected in some cultured human melanoma cell lines $(8,9)$. Earlier attempts to detect alpha-MSH binding sites in cultured human melanoma cells were inconclusive $(9,10)$, but one group has recently confirmed the presence of an MSH binding protein with the use of biologically active MSH tracer peptides $(11,12)$. Nevertheless, it is not clear to what extent the behavior of tumor cells in culture reflects that in vivo, since cultured melanocytic cells have been shown to express an altered profile of cell surface proteins such as growth factor receptors, as compared with the corresponding cells in situ (13).

To assess the potential biological roles of endogenous melanotropins in human melanoma and the potential therapeutic value of MSH receptor-targeted agents, we designed these studies to determine the presence or absence and the binding properties of melanotropin receptors in human melanoma cells in situ. We have recently developed methods for the characterization of MSH receptors in cultured B16 mouse melanoma cells in vitro and in tumor tissue in situ $(5,14)$ using a radiolabeled $\mathrm{MSH}$ tracer that has full biological activity and potency (14), and is known to detect functional MSH receptors (5). The results, recently presented in preliminary form (15), indicate that melanoma cells of some metastatic tumors express MSH receptors, which has implications for the basic biology of melanoma as well as for the therapeutic utility of MSH receptor-targeted agents.

\section{Methods}

Patients and tumor specimens. Tumor specimens were obtained from patients undergoing therapeutic excision of known or suspected melanoma metastases. 12 patients were studied (31-77 yr of age; 7 female, 5 male). Tumors of 11 patients were confirmed histologically to be metastatic melanomas; one was a leiomyoma. Tissues were placed in $0.9 \%$ $\mathrm{NaCl}$ and dissected free of fat, connective tissue, and accessible necrotic areas on ice within $3 \mathrm{~h}$ of excision. Cubes of tissue were dissected from up to five areas representative of the gross morphology of each tumor and placed in chilled OCT compound (Miles Laboratories Inc., Naperville, IL), frozen at $-23^{\circ} \mathrm{C}$, and stored in sealed bags at $-70^{\circ} \mathrm{C}$ 
until sectioning. 8- $\mu \mathrm{m}$-thick cryosections were prepared using modifications (5) of the method of Herkenham and Pert (16).

Peptides. Alpha-MSH and $\mathrm{Nle}^{4}$, D-Phe ${ }^{7}$-alpha-MSH (NDP-MSH) were obtained from Bachem Inc. (Torrance, CA) and Peninsula Laboratories, Inc. (Belmont, CA). The respective peptides from these two sources have proven consistently comparable in potency in RIA and mouse melanoma binding assays and bioassays (Tatro, J. B., unpublished observations). Synthetic human $\mathrm{ACTH}_{1-39}$ and somatostatin were obtained from Peninsula Laboratories, Inc. Substance P was obtained from Boehringer Mannheim GmbH (Mannheim, FRG).

Preparation of $\left[{ }^{125} I\right] N D P-M S H$. NDP-MSH was iodinated and purified as described (14). Briefly, $4 \mu \mathrm{g}$ peptide was iodinated using Enzymobeads (Bio-Rad Laboratories, Richmond, CA) and purified by reverse-phase chromatography. Fractions were pooled from the portion of the eluted peak showing greatest immunoreactivity and specific activity (typically $1.2-2.0 \times 10^{6} \mathrm{Ci} / \mathrm{mol}$ ). This material has consistently shown biological activity (stimulation of melanogenesis) virtually identical to that of uniodinated NDP-MSH in B16 mouse melanoma cells (14).

In situ binding studies. Serial slide-mounted, dried, unfixed frozen tissue sections were preincubated for $15 \mathrm{~min}$ at $23^{\circ} \mathrm{C}$ in a buffer consisting of $50 \mathrm{mM}$ Tris- $\mathrm{HCl}, 140 \mathrm{mM} \mathrm{NaCl}, 2.5 \mathrm{mM} \mathrm{CaCl}_{2}$, and 1.2 $\mathrm{mM} \mathrm{MgCl}$, $\mathrm{pH}$ 7.2. Matched sets of serial sections were then incubated for $60 \mathrm{~min}$ in a similar buffer with the addition of BSA $(0.25 \%)$ ascorbic acid $(0.6 \%)$, aprotinin $(500 \mathrm{KIU} / \mathrm{ml})$, and $\left[{ }^{125} \mathrm{I}\right] \mathrm{NDP}-\mathrm{MSH}$ $\left(2.5-5.0 \times 10^{5} \mathrm{cpm} / \mathrm{ml} ; \sim 0.15-0.3 \mathrm{nM}\right)$ in the presence or absence of unlabeled peptides. To terminate binding reactions, slides were washed in ice-cold buffer ( $10 \mathrm{mM}$ sodium phosphates, $154 \mathrm{mM} \mathrm{NaCl}$, and 1.2 $\mathrm{mM} \mathrm{MgCl}, \mathrm{pH}$ 7.2), dried under a cold air stream, and fixed in hot paraformaldehyde vapors under vacuum $(5,16)$. After ventilating the slides in a fume hood overnight, autoradiographic detection of $\left[{ }^{125} \mathrm{I}\right]$ NDP-MSH binding was performed by one or both of two methods.

For assessment of histological patterns of binding site distribution by bright- and dark-field microscopy, matched pairs of serial sections were coated with NTB2 liquid photographic emulsion (Eastman Kodak Co., Rochester, NY) diluted 1:1 with $0.6 \mathrm{M}$ ammonium acetate, exposed in the dark at $4^{\circ} \mathrm{C}$ for 8-14 d, developed for $2.5 \mathrm{~min}$ in D19 developer (Eastman Kodak Co.), and counterstained with hematoxylin-eosin or methyl green. In 10 of 11 cases a second set of sections was applied directly to $\mathrm{x}$-ray film $\left(\left[{ }^{3} \mathrm{H}\right]\right.$ Ultrofilm; LKB Instruments, Inc., Gaithersburg, MD), and exposed for 7-21 $\mathrm{d}$ at room temperature. The films were used for quantitative comparisons of relative binding levels under different conditions and in different patients by means of image analysis. In control experiments, tissue sections that were incubated in the absence of tracer did not produce signals above the nontissue background level, either in liquid emulsions or on x-ray films. This was true even for samples containing highly melanized areas, thus ruling out chemography as an artifactual source of signal.

Image analysis. Video images of film autoradiograms were digitized using a Gordon transilluminator and EyeCom model 700SV image scanner (Spatial Data Systems, Inc.; Goleta, CA), and analyzed using a VAX 11/780 computer, Gould/DeAnza ID5424 color display/image processor, and the DISPEX program of the Image Analysis Laboratory, Tufts-New England Medical Center. For each film autoradiogram analyzed, mean optical densities of replicate square fields were obtained for background (nontissue) areas immediately surrounding the area of film overlying the tissue (two to four readings), and for film areas overlying contiguous tissue areas (two to five readings per section). In specimens heterogeneous with respect to histomorphological tissue types, only contiguous areas composed primarily of viable melanoma cells were analyzed. The relative intensity of peptide-specific [ ${ }^{125}$ I]NDP-MSH binding in a given tissue was then calculated according to the formula:

$O D_{\text {specific }}=\left(O D_{\text {tiss }}-O D_{\text {bkg }}\right)_{\text {control }}-\left(O D_{\text {tiss }}-O D_{\text {bkg }}\right)_{\text {peptide }, ?}$

where OD = mean optical density, expressed as a value on the 256level gray scale; $\mathrm{OD}_{\text {specific }}=\mathrm{MSH}$-induced decrease in $\mathrm{OD}$, used as an index of binding intensity; tiss = tissue; bkg = background; control $=$ incubated with tracer only; and peptide = incubated with tracer plus unlabeled competing peptide. For each variable studied, this analysis was performed on one or two sections per slide and one to three slides per experimental condition studied. In separate experiments, using a series of [ ${ }^{125}$ I]NDP-MSH radioactivity concentration reference standards prepared in liver paste and processed comparably to tumor specimens (17), it was determined that the concentration-response relationship for film OD response to increasing concentrations of tissue radioactivity was approximately linear within the observed range of OD.

Specimens were designated as showing detectable or undetectable specific binding according to the following criteria. In the presence of $10^{-6} \mathrm{M}$ alpha-MSH, a mean decrease in tissue-bound radioactivity giving a change in OD of $>3$ gray levels in any given tissue specimen, an amount easily perceptible by eye, was considered a positive indication of the presence of specific MSH binding sites in the respective patients. Specimens that were classified as showing undetectable specific binding gave an alpha-MSH-induced change in integrated OD of $\leq 1$ gray level. In two patients the apparent absence of specific [ $\left.{ }^{125} \mathrm{I}\right]-$ NDP-MSH binding in liquid emulsion-coated tissue sections was verified by performing blind, replicate counts of silver grains on dark-field photomicrographs, rather than by analysis of digitized $x$-ray film images (original magnification $\times 108$, four fields per photomicrograph, three photomicrographs per tissue section; data not shown).

Statistics. Data are presented as means \pm SEM unless indicated otherwise. Differences in means between patient groups and experimental conditions were tested for significance using analysis of variance for repeated measures and $t$ tests (18). Results of competitive binding experiments were analyzed using the RIA-AID computer program (Robert Maciel Associates, Inc., Arlington Heights, MA).

\section{Results}

Demonstration and distribution of MSH binding sites in tumor tissue. Autoradiographic studies of $\left[{ }^{125} \mathrm{I}\right] \mathrm{NDP}-\mathrm{MSH}$ binding in situ in tumor tissue sections showed that specimens of most patients contained specific MSH binding sites. Tracer binding was distributed in a heterogeneous pattern that was highly correlated with tissue morphology (Figs. 1 and 2). Specific binding of tracer, indicated by its inhibition in the presence of $10^{-6} \mathrm{M}$ alpha-MSH, was restricted to melanoma cells. Specific binding was not detectable in connective tissue (Fig. 1). Areas containing inflammatory cells or necrosis showed high levels of tracer localization, but of a type that was nonspecific, as indicated by its persistence in the presence of alpha-MSH (Figs. 1 and 2). While many of the cells showing high nonspecific binding in emulsion-coated sections were pigmented (Fig. 1), those that were clearly identifiable as to cell type were melanin-laden macrophages. No tracer binding was observed in normal lymphoid tissue, which was studied in uninvolved lymph nodes of a patient with lymph node melanoma metastases.

Time course of binding. Specific binding of $\left[{ }^{125}\right.$ I]NDPMSH to melanoma cells in situ was time dependent, reaching half-maximal and maximal levels at $\sim 45 \mathrm{~min}$ and $2-4 \mathrm{~h}$, respectively (Fig. 3). Further studies were therefore carried out using 2-h incubations.

Peptide specificity of melanotropin binding sites. To assess the melanotropin specificity of melanoma MSH binding sites and to test whether they bind melanotropins with high affinity, we next determined the potencies of a series of melanotropic peptides, NDP-MSH, alpha-MSH, and ACTH, in competing with [ ${ }^{125}$ I]NDP-MSH for binding. Each of the three melano- 

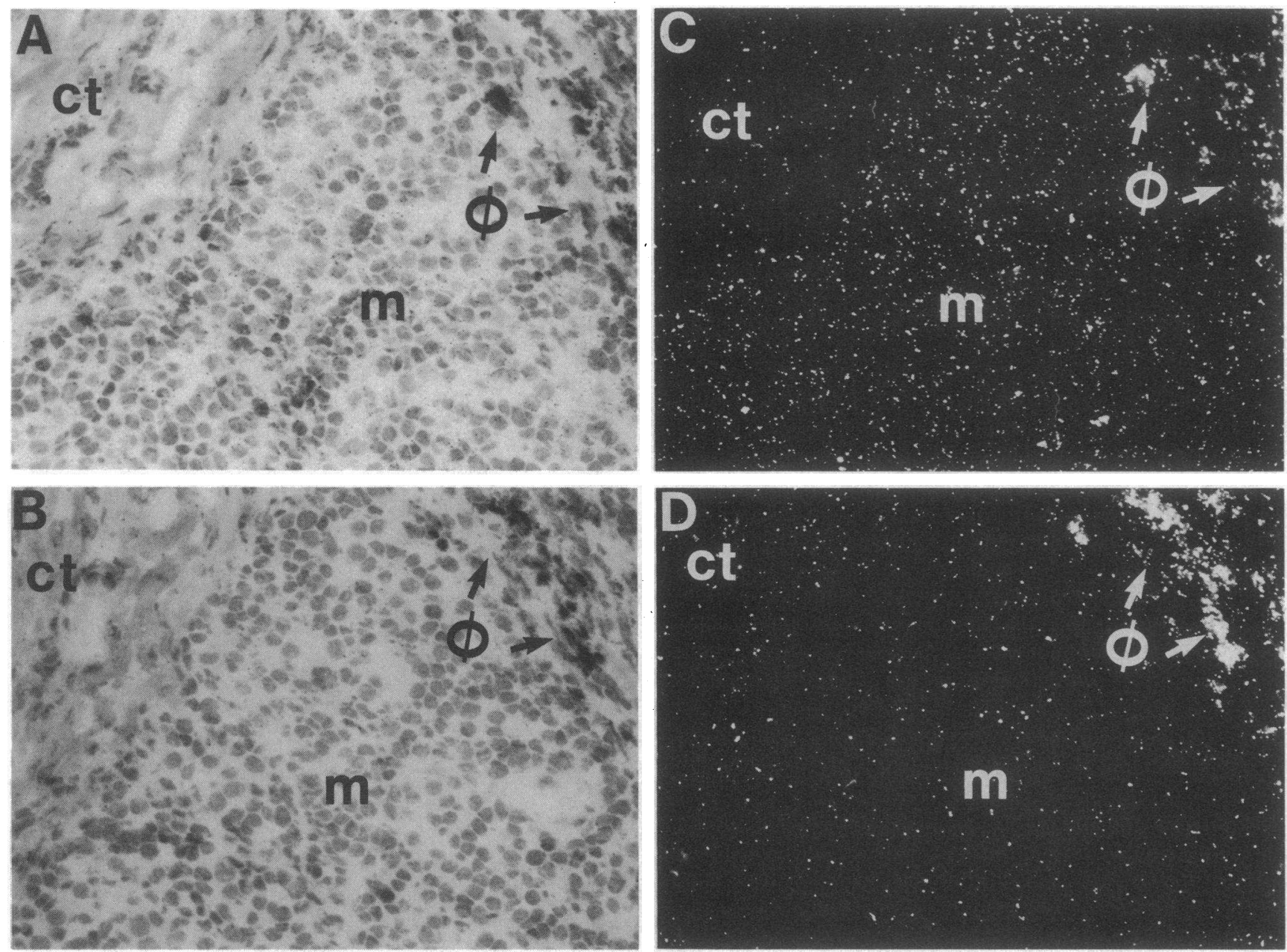

Figure 1. Microscopic autoradiographic localization of specific [ $\left.{ }^{125} \mathrm{I}\right]$ NDP-MSH binding in metastatic melanoma tissue. $m$, Melanoma cells; $c t$, connective tissue; $p h i$, pigmented macrophages. $A$ and $B$, Serial frozen, incubated, and emulsion-coated sections (hematoxylin and eosin). Original magnification $\times 200$. $C$ and $D$, Dark-field illumination of respective areas shown in $A$ and $B . A$ and $C$, Section exposed to [ $\left.{ }^{125} I\right] N D P-M S H$ only. $B$ and $D$, Section exposed to [ $\left.{ }^{125} I\right]$ NDP-MSH plus $1 \mu \mathrm{M}$ alpha-MSH. Silver grains appear as uniform dark specks in brightfield and as uniform bright specks in darkfield. Density of the grain distribution indicates the relative concentration of bound radioactivity. Dense grain distribution over melanoma cells ( $A$ and $C ; m$ in center of photographs) is markedly decreased in the presence of alpha-MSH $(B$ and $D$ ), indicating presence of specific binding sites. In contrast, binding in area infiltrated by macrophages ( $p h i)$, located predominantly in fibrous tissue and containing phagocytized melanin, is nonspecific, as indicated by high grain densities in both absence $(A$ and $C)$ and presence $(B$ and $D)$ of $10^{-6} M$ alpha-MSH. Bright appearance of pigmented macrophages in darkfield photos $(p h i)$ is due to the refractile nature of the pigment in addition to high local grain density. Connective tissue $(c t)$ shows low grain density in areas lacking inflammatory cells, indicating absence of specific binding.

tropins tested inhibited tracer binding to melanoma cells in a concentration-dependent fashion (Fig. 4). Alpha-MSH and NDP-MSH were of comparable potency overall (approximate $\left.\mathrm{EC}_{50}=1-2 \times 10^{-9} \mathrm{M}\right)$ in inhibiting $\left[{ }^{125} \mathrm{I}\right] \mathrm{NDP}-\mathrm{MSH}$ binding (Fig. $4 \mathrm{~A}$ ), whereas ACTH was less potent (Fig. $4 \mathrm{~B}$ ). In contrast, the nonmelanotropic peptides substance $P\left(10^{-6} \mathrm{M}\right)$ and somatostatin $\left(10^{-6} \mathrm{M}\right)$, used as controls, did not inhibit tracer binding to tumor cells in tissue sections of the same series (Table I). None of the tested peptides inhibited tracer localization in inflammatory tissue.

Prevalence of MSH receptor expression in metastatic melanoma patients. To determine the prevalence of specific melanotropin binding site expression, the relative intensity of specific binding in different patients was assessed by image analysis of film autoradiograms. The data were obtained from three separate experiments. In each experiment, melanoma speci- mens of known receptor-positive patients, and in some cases specimens of known receptor-positive mouse melanomas as well (5), were tested. This provided positive controls for each experiment and allowed for comparative assessment of the relative binding intensities in different patients.

Metastatic melanoma specimens from 8 of 11 patients showed some degree of specific $\left[{ }^{125} \mathrm{I}\right]$ NDP-MSH binding. A subgroup of three patients showing relatively greater specific binding of $\left[{ }^{125} I\right] N D P-M S H$ binding was classified as having high-level receptor expression, while the remaining subgroup of five receptor-positive patients was classified as having lowlevel receptor expression (Table II). Representative x-ray film autoradiograms of tissue specimens showing high and low specific binding of $\left[{ }^{125} \mathrm{I}\right] \mathrm{NDP}-\mathrm{MSH}$ are shown in Fig. 5. The greater responses in the high-level subgroup were associated with both a greater percentage inhibition of total tracer bind- 

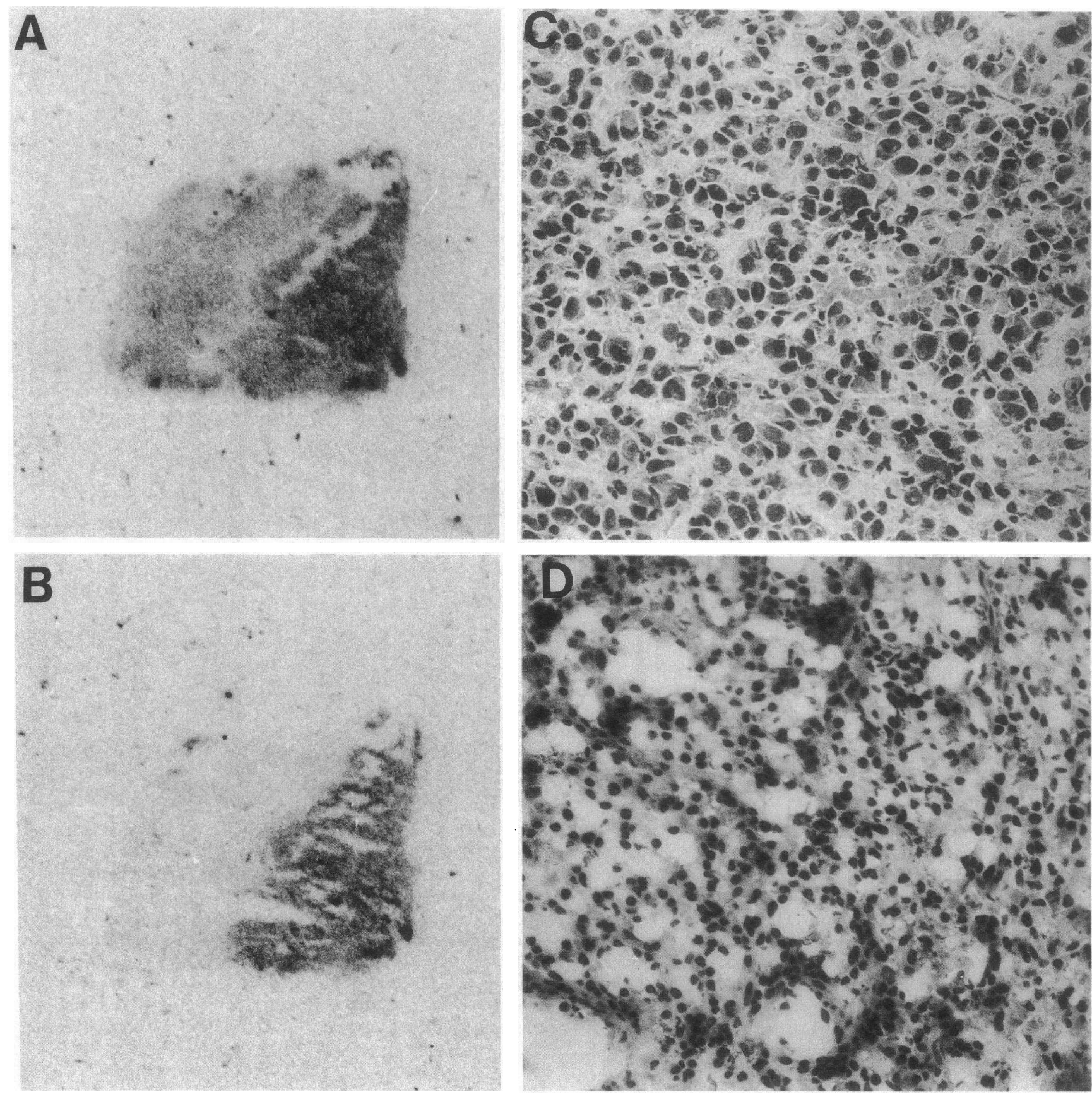

Figure 2. Melanoma cell-specific localization of stereospecific [ ${ }^{125}$ I]NDP-MSH binding sites in serial sections of metastatic tumor showing mixed morphology. $A$ and $B$, x-ray film autoradiograms of serial sections exposed to [ ${ }^{125}$ I]NDP-MSH only $(A)$ and to [ ${ }^{125}$ I]NDP-MSH plus 1 $\mu \mathrm{M}$ alpha-MSH $(B) . C$, Histological appearance of area corresponding to left-hand portion of each autoradiogram, which shows marked inhibition of binding in the presence of alpha-MSH. This region contains primarily melanoma cells. $D$, Histological appearance of tissue area corresponding to right-hand portions of autoradiograms, which show only nonspecific tracer uptake as indicated by its persistence in the presence of alpha-MSH. This region is composed of inflammatory tissue. Hematoxylin and eosin, original magnification $\times 200$.

ing in the presence of alpha-MSH (Table II) and higher absolute binding levels (e.g., Figs. 2 and $5, A$ and $B$ ) than those observed in the low-level subgroup (Fig. 5, $C$ and $D$ ). Metastatic melanomas of three patients did not show detectable specific binding (Table II). A specimen of leiomyoma did not show detectable binding. The leiomyoma and one of the receptor-negative melanoma specimens were analyzed by performing replicate counts of silver grains on liquid emulsion- coated slides, rather than by image analysis of film autoradiograms (see Methods).

In one patient showing high levels of specific [ ${ }^{125}$ I]NDPMSH binding, tissue specimens obtained from five different sites within one large tumor, and also from tumors excised on a total of three separate occasions, were tested. All samples from this patient showed specific $\left[{ }^{125} \mathrm{I}\right] \mathrm{NDP}-\mathrm{MSH}$ binding. When studied within a single experiment, specific binding in 


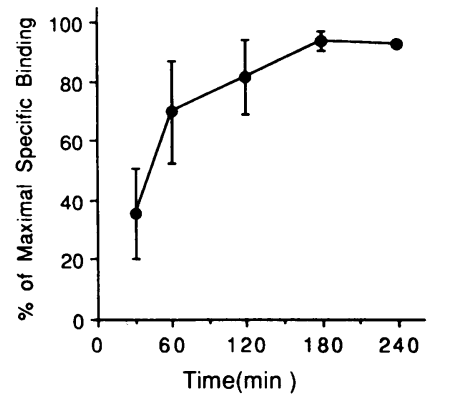

Figure 3. Time course of specific [ ${ }^{125}$ I]NDP-MSH binding to melanoma tissue sections in situ. Shown are results in tumor specimens of three patients showing high levels of specific tracer binding. Results were first expressed as percent of maximal specific binding for each specimen, as assessed by image analysis of digitized film autoradiograms, then pooled. Only two specimens were tested at $240 \mathrm{~min}$. the multiple intratumor specimens varied over a 10 -fold range of intensity (examples shown in Figs. 2 and 5, $A$ and $B$ ), but high-level expression was observed in all the specimens.

\section{Discussion}

These studies demonstrate for the first time that specific melanotropin binding sites are expressed in human melanoma in situ. The evidence supports the hypothesis that these binding sites represent functional receptors since they exhibit high affinity, melanotropin specificity, and tissue specificity (i.e., localization of specific binding sites in melanoma cells rather than in associated nontumor tissues). These properties likewise have been demonstrated recently for the functional MSH receptors of highly MSH-responsive B16 mouse melanoma cell sublines $(5,6)$.

The presence of melanotropin receptors on melanoma cells is of interest both because of the potential role of endogenous melanotropins in melanoma growth or metastasis, and also because the MSH receptor may represent a relatively tissuespecific surface protein that may be used in targeting melanoma cells for delivery of clinically useful antineoplastic substances. Among different patients, levels of receptor expression
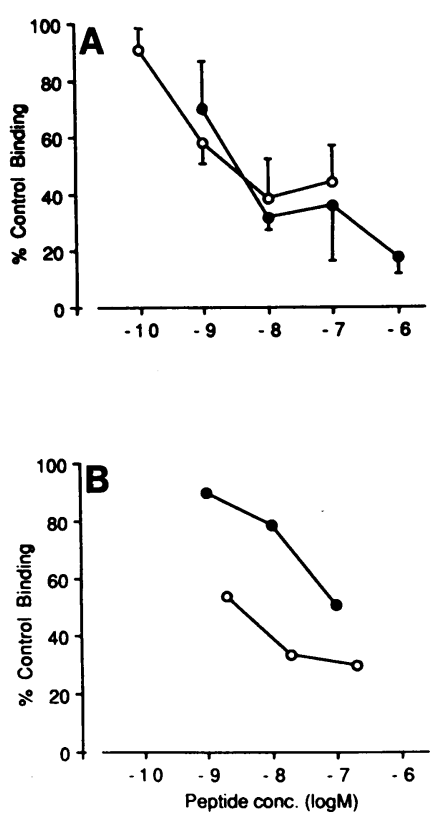

Figure 4. Concentration-response relationships for inhibition by melanotropins of $\left[{ }^{125} \mathrm{I}\right]$ NDP-MSH binding to melanoma tissue sections. Each point represents binding in terms of percent of control binding (i.e., binding in the absence of added unlabeled peptides) as measured by analysis of digitized $x$-ray film autoradiographs. Specimens studied were the same three tumor specimens for which timecourse data are shown in Fig. 3. $A$, Responses to alpha-MSH $(\bullet)$ and NDP-MSH (O). $B$, Responses to ACTH. In $B$, results in two patients were pooled (o); the results of the experiment in the third patient, in which different ACTH concentrations were tested, are presented separately $(\bullet)$.
Table I. Peptide Specificity of MSH Binding Sites in Metastatic Melanoma

\begin{tabular}{lccc}
\hline Peptide & Concentration & $n$ & $\begin{array}{c}\text { \% Inhibition of } \\
\text { control tracer } \\
\text { binding in situ }\end{array}$ \\
\hline Alpha-MSH & $M$ & & \\
Substance P & $10^{-6}$ & 3 & $64.4 \pm 14.0^{*}$ \\
Somatostatin & $10^{-6}$ & 3 & $-23.3 \pm 17.9$ \\
& $10^{-6}$ & 3 & $-3.5 \pm 9.8$ \\
\hline
\end{tabular}

* $P=0.044$ vs. control.

varied from undetectable to intense, which may account in part for the reported heterogeneity in cultured human melanoma cell responses to alpha-MSH (8). Tumors removed from one patient on three separate occasions consistently showed high levels of specific MSH binding, suggesting some degree of homogeneity of receptor expression within tumor deposits of an individual patient.

Although melanotropin responsiveness and MSH receptors in cultured mouse melanoma cell lines have been extensively studied $(1,5-7,14,19)$, the actions of melanotropins in human melanoma are poorly understood. Varying effects of MSH on cultured human melanoma cell tyrosinase activity $(8$, 9) have been reported. MSH also induces cytoplasmic granule accumulation (20) and stimulates cyclic AMP accumulation in some human melanoma cultures (9) as well as in normal melanocytes (21). Characterization of human MSH receptors has been impossible until very recently, since valid methodologies for their detection have been unavailable. In earlier studies using either immunocytochemical methods (9) or radiolabeled alpha-MSH (10), MSH binding was detected, but the reports failed to document whether the binding was specific (9) or whether the MSH tracer was biologically active (10). More recently, a specific MSH binding protein has been detected in cultured human cell lines with the use of biologically active photolabeled (11) and radiolabeled (12) alpha-MSH derivatives.

Like the MSH receptor of B16 mouse melanoma cells (5-7) and tumors (5), that of human melanomas in situ shows high apparent affinities for melanotropins (nanomolar range). The relative potencies of the peptides in human melanoma

Table II. Frequency of Expression of Specific MSH Binding Sites in Human Metastatic Melanoma

\begin{tabular}{lcc}
\hline $\begin{array}{l}\text { Relative intensity of specific } \\
\text { binding of }{ }^{125} \text { I]NDP-MSH }\end{array}$ & No. of cases & $\begin{array}{c}\text { \% Inhibition of control tracer } \\
\text { binding by alpha-MSH }\end{array}$ \\
\hline & & mean \pm SEM \\
High & 3 & $63.6 \pm 6.6^{*}$ \\
Low & 5 & $27.6 \pm 4.4$ \\
Undetectable & 3 & 6.0 \\
Total & 11 &
\end{tabular}

* $P=0.012$ vs. "Low" subgroup. In the undetectable subgroup $\mathrm{x}$-ray autoradiograms were available for only two patients; the third was analyzed by grain counts in liquid emulsion-coated slides. 

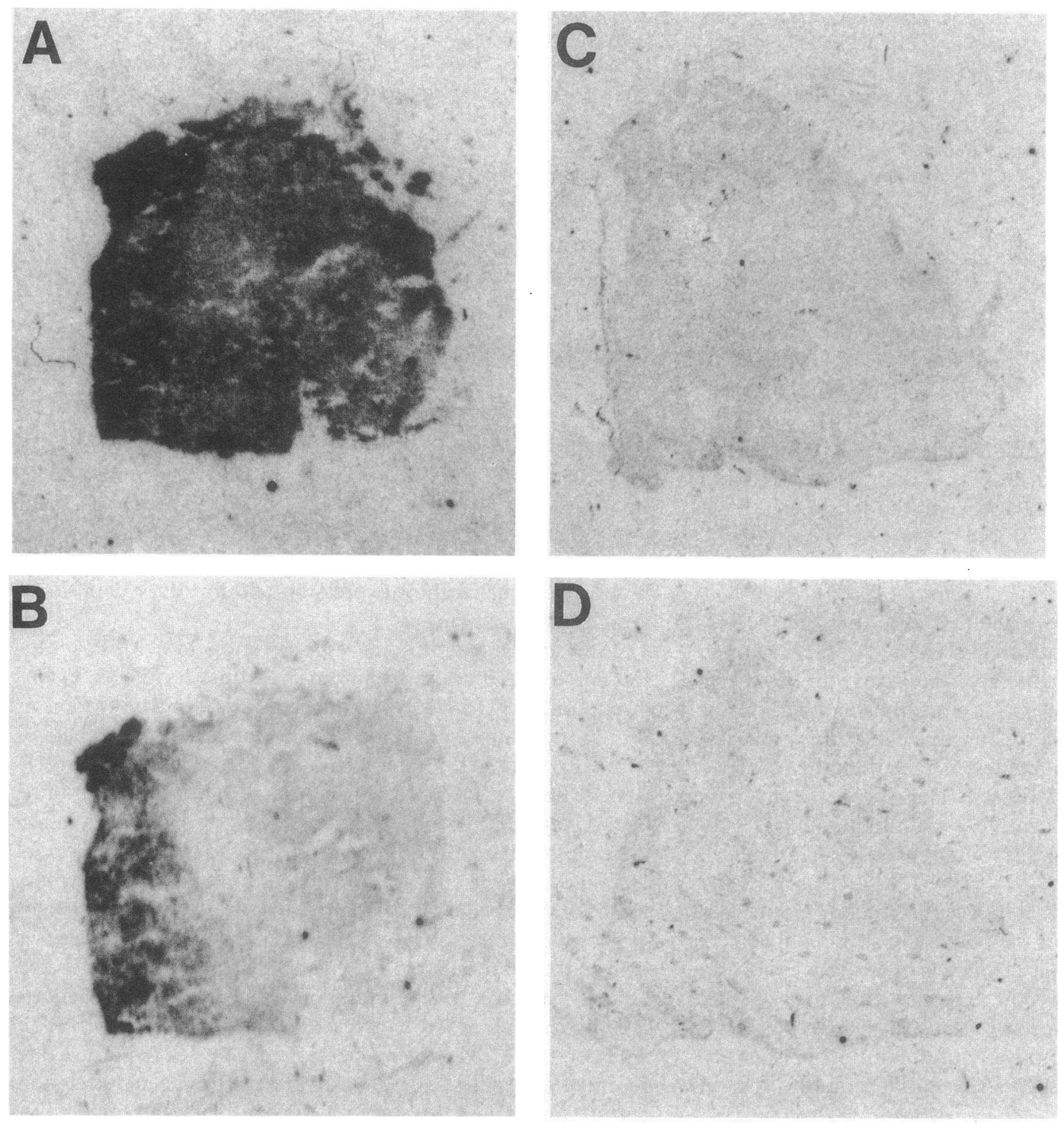

Figure 5. Representative $x$-ray film autoradiograms of tumor specimens showing high $(A$ and $B)$ and low $(C$ and $D$ ) levels of specific $\left.{ }^{[25} \mathrm{I}\right]-$ NDP-MSH binding in situ. Autoradiograms of serial sections exposed to [ ${ }^{125}$ I] NDP-MSH only $(A$ and $C$ ) and to $\left[{ }^{125} \mathrm{I}\right] \mathrm{NDP}$ MSH plus $1 \mu \mathrm{M}$ alphaMSH ( $B$ and $D$ ). All specimens were composed primarily of melanoma cells. Area corresponding to the leftmost portions of autoradiograms in $A$ and $B$ also contained numerous pigmented cells; those that were identifiable histologically were macrophages showing typical nonspecific binding. tissues (NDP-MSH = alpha-MSH $\geq$ ACTH) are not as clearly distinct as those (i.e., NDP-MSH > alpha-MSH > ACTH) reported in murine $B 16$ melanoma cells $(5,6)$ and tissue sections (5); however, firm conclusions regarding these properties will require studies of additional patients to rule out differences attributable to receptor heterogeneity of melanoma tumor populations (12).

While we have recently shown that MSH receptors are widely distributed in vivo in rodents (14), it is not known whether cells of nonmelanocytic tissues of humans express MSH receptors. In mice, alpha-MSH has immunomodulatory effects on certain lymphoid targets, whereas NDP-MSH does not $(22,23)$. This suggests that multiple melanotropin receptor subclasses may exist, since NDP-MSH is a superpotent melanotropin agonist in melanocytic cells (24). Accordingly, lymphoid tissues of normal mice or rats show undetectable or very low specific uptake of $\left[{ }^{125} I\right] N D P-M S H$ in vivo (14). In a patient having melanoma metastases of lymph nodes, uninvolved lymph nodes showed no evidence of tracer binding, suggesting that normal human lymphoid cells likewise do not express receptors recognizing NDP-MSH. Areas heavily infil- trated by inflammatory cells showed only nonspecific binding of [ ${ }^{125}$ I]NDP-MSH, which was also observed in necrotic tissue and is most likely attributable to proteolytic degradation of the tracer. The present results do not rule out the potential presence of melanotropin receptors in occasional inflammatory cells, which may be obscured by nonspecific binding in neighboring cells, nor do they exclude the possibility that occasional melanoma cells may exhibit high levels of nonspecific binding. Nevertheless, where histological identification of cell types was possible in the frozen sections, specific binding was restricted to melanoma cells, indicative of a high degree of cell-type specificity of MSH receptor expression.

The presence of MSH receptors in melanoma raises the possibility that the activities of melanoma cells in vivo may be modulated by endogenous melanotropins. Recent studies of cultured mouse melanoma cells are suggestive of a role of melanotropins in metastasis (25-27), control of cell shape (28), and growth (29-32). Alpha-MSH also stimulates proliferation in A375 human melanoma cells (26), in a panel of human melanoma cell lines (33), and in cultured normal human melanocytes (34). It will therefore be of interest to determine 
whether the level of expression of MSH receptors is related to the stage of tumor progression and/or the degree of aggressiveness of metastasis in melanoma.

In postulating a role of endogenous melanotropins in control of melanoma cell behavior, it is implicit that tumor cells must be exposed to melanotropins in vivo. In fact, the gene encoding the melanotropin precursor, proopiomelanocortin, is expressed in diverse nonpituitary sites, including lymphoid cells and malignant tumors (35-37). Thus, although alphaMSH and ACTH normally circulate in the blood of humans at only low picomolar concentrations $(37,38)$, locally produced melanotropins may have significant biological effects. Full assessment of the potential roles of endogenous melanotropins will require determination of which additional processed forms of MSH are present locally or in the circulation, and testing of their effects in melanoma bioassay systems.

The actions of endogenous melanotropins on melanoma may be modulated by interactions with cytokines and the local environment. Interferons, which are present locally and may participate in immune responses to melanoma (39), enhance MSH responses and receptor expression in mouse melanoma cells (40). Moreover, the actions of IL-1, a cytokine that is directly toxic to melanoma cells (41), are antagonized by alpha-MSH in multiple target tissues $(18,19,42)$, possibly through a postreceptor mechanism (43). The presence of melanotropin receptors in melanoma thus raises the possibility that melanotropins may affect melanoma cell survival by modulating the actions of cytokines on melanoma cells. Conversely, epidermal-derived thymocyte activating factor, a cytokine-like factor in skin which is highly related to IL-1 (44), antagonizes MSH action in S91 mouse melanoma cells (45). In mouse melanoma cells laminin (46) and collagen (30) augment responsiveness to $\mathrm{MSH}$, suggesting a role of the extracellular matrix in controlling melanotropin responsiveness. Together, the available evidence suggests that melanoma cells may be influenced in vivo by complex and bidirectional interactions between melanotropins, substratum, and immune mediators produced in lymphoid cells and skin, a feature not predicted from earlier in vitro studies.

Several groups have undertaken the development of MSH receptor-targeted agents as potential therapeutic tools for treatment of malignant melanoma (2-4). The present results support the premise of these strategies, since the majority of human metastatic melanomas appear to express detectable specific binding sites, but also indicate that some patients would not be candidates for these therapies. Since MSH receptors are found in some tumors but not in all, the in situ binding assay may be an effective method with which to evaluate patients as candidates for treatment with MSH-linked hybrid therapeutic agents, and to identify other potential sites of toxicity. In situ localization is critical, since the nonspecific binding associated with necrotic and inflammatory tissues may obscure the presence of specific MSH receptors if specimens are assayed by other methods.

In summary, the detection of specific melanotropin receptors in metastatic melanoma in situ raises new questions about the biological roles of proopiomelanocortin-derived peptides in human melanoma. It also increases the likelihood that hybrid MSH-linked therapeutic agents would be useful in the treatment of certain melanoma patients, and provides a potential approach for screening of candidate patients for such therapies. It will be of interest to determine whether normal epidermal melanocytes and cells of other stages of melanocytic tumor progression, such as nevus melanocytes and primary melanoma (13), share the property of MSH receptor expression, and to define the factors that regulate receptor expression and function.

\section{Acknowledgments}

This work was supported by National Institutes of Health grants R01MH-44694-01 (to Dr. Tatro), R01-DK-16884-17 (to Dr. Reichlin), and RR-00054, and by American Cancer Society grant RD-285 (to Dr. Tatro).

We thank Dr. Ronald Lechan and Dr. Stephen Naber for helpful discussions, and Dr. Debbie Beasley for reviewing the manuscript.

\section{References}

1. Wong, G., J. Pawelek, M. Sansone, and J. Morowitz. 1974. Response of mouse melanoma cells to melanocyte stimulating hormone. Nature (Lond.). 248:351-354.

2. Varga, J. M., N. Asato, S. Lande, and A. B. Lerner. 1977. Melanotropin-daunomycin conjugate shows receptor-mediated cytotoxicity in cultured murine melanoma cells. Nature (Lond.). 267:56-58.

3. Murphy, J. R., W. Bishai, M. Borowski, A. Miyanohara, J. Boyd, and S. Nagle. 1986. Genetic construction, expression, and melanomaselective cytotoxicity of a diphtheria toxin-related alpha-melanocytestimulating hormone fusion protein. Proc. Natl. Acad. Sci. USA. 83:8258-8262.

4. Liu, M. A., S. R. Nussbaum, and H. N. Eisen. 1988. Hormone conjugated with antibody to CD3 mediates cytotoxic $\mathrm{T}$ cell lysis of human melanoma cells. Science (Wash. DC). 239:1227-1230.

5. Tatro, J. B., M. L. Watson, B. L. Lester, and S. Reichlin. 1989. Melanotropin receptors of murine melanoma characterized in cultured cells and demonstrated in experimental tumors in situ. Cancer Res. 50:1237-1242.

6. Siegrist, W., M. Oestreicher, S. Stutz, J. Girard, and A. N. Eberle. 1988. Radioreceptor assay for alpha-MSH using mouse B16 melanoma cells. J. Recept. Res. 8:323-343.

7. Gerst, J. E., J. Sole, J. P. Mather, and Y. Salomon. 1986. Regulation of adenylate cyclase by beta-melanotropin in the M2R melanoma cell line. Mol. Cell. Endocrinol. 46:137-147.

8. Fuller, B. B., and F. L. Meyskens, Jr. 1981. Endocrine responsiveness in human melanocytes and melanoma cells in culture. JNCI (J. Natl. Cancer Inst.). 66:799-802.

9. Legros, P., J. Coel, A. Doyen, P. Hanson, N. Van Tieghem, A Vercammen-Grandjean, J. Fruhling, and F. J. Lejeune. 1981. Melanocyte-stimulating hormone binding and biological activity in a human melanoma cell line. Cancer Res. 41:1539-1544.

10. Ghanem, G. E., C. Communale, A. Libert, A. VercammenGrandjean, and F. J. Lejeune. 1988. Evidence for alpha-melanocytestimulating hormone receptors on human malignant melanoma cells. Int. J. Cancer. 41:248-255.

11. Solca, F., W. Siegrist, R. Drozdz, J. Girard, and A. N. Eberle. 1989. The receptor for alpha-melanotropin of mouse and human melanoma cells: application of a potent photoaffinity label. J. Biol. Chem. 264:14277-14281.

12. Siegrist, W., F. Solca, S. Stutz, L. Giuffre, S. Carrel, J. Girard, and A. N. Eberle. 1989. Characterization of receptors for alpha-melanocyte-stimulating hormone on human melanoma cells. Cancer Res. 49:6352-6358.

13. Herlyn, M., W. H. Clark, U. Rodeck, M. L. Mancianti, J. Jambrosic, and H. Koprowski. 1987. Biology of disease: biology of tumor progression in human melanocytes. Lab. Invest. 56:461-474.

14. Tatro, J. B., and S. Reichlin. 1987. Specific receptors for alphamelanocyte-stimulating hormone are widely distributed in tissues of rodents. Endocrinology. 121:1900-1907. 
15. Tatro, J. B., M. L. Watson, T. Smith, M. Atkins, and B. L. Lester. 1989. Malignant melanoma tissues of humans and mice express specific receptors for alpha-melanocyte stimulating hormone. Proc. 71st Annu. Mtg. Endocr. Soc. 429. (Abstr.)

16. Herkenham, M., and C. B. Pert. 1982. Light microscopic localization of brain opiate receptors: a general autoradiographic method which preserves tissue quality. J. Neurosci. 28:1129-1149.

17. Unnerstall, J. R., M. J. Kuhar, D. L. Niehoff, and J. M. Palacios. 1981. Benzodiazepine receptors are coupled to a subpopulation of gamma-aminobutyric acid (GABA) receptors: evidence from a quantitative autoradiographic study. J. Pharmacol. Exp. Ther. 218:797804.

18. Dixon, W. J., M. B. Brown, L. Engelman, M. A. Hill, and R. I. Jennrich. 1988. BMDP Statistical Software Manual. University of California Press, Berkeley, CA. 1234 pp.

19. Varga, J. M., A. Dipasquale, J. Pawelek, J. S. McGuire, and A. B. Lerner. 1974. Regulation of melanocyte stimulating hormone action at the receptor level: discontinuous binding of hormone to synchronized mouse melanoma cells during the cell cycle. Proc. Natl. Acad. Sci. USA. 71:1590-1594.

20. Packard, B. S. 1987. Identification of a synthetic nonapeptide sequence that inhibits motility in culture of a melanoma subclone that possesses a high metastatic potential. Proc. Natl. Acad. Sci. USA. 84:9015-9019.

21. Ranson, M., S. Posen, and R. S. Mason. 1988. Human melanocytes as a target tissue for hormones: in vitro studies with 1-alpha-25, dihydroxyvitamin $D_{3}$, alpha-melanocyte stimulating hormone, and beta-estradiol. J. Invest. Dermatol. 91:593-598.

22. Cannon, J. G., J. B. Tatro, S. Reichlin, and C. A. Dinarello. 1986. Alpha-melanocyte stimulating hormone inhibits immunostimulatory and inflammatory actions of interleukin 1. J. Immunol. 137:2232-2236.

23. Rheins, L. A., A. L. Cotleur, R. S. Kleier, W. B. Hoppoenjans, D. N. Sauder, and J. J. Nordlund. 1989. Alpha-melanocyte stimulating hormone modulates contact hypersensitivity responsiveness in C57/ BL6 mice. J. Invest. Dermatol. 93:511-517.

24. Sawyer, T. K., V. J. Hruby, P. S. Darman, and M. E. Hadley. 4-Norleucine, 7-D-phenylalanine-alpha-melanocyte-stimulating hormone: a cyclic alpha-melanotropin exhibiting superagonist biological activity. Proc. Natl. Acad. Sci. USA. 79:5754-5758.

25. Sheppard, J. R., T. P. Koestler, S. P. Corwin, C. Buscarino, J. Doll, B. Lester, R. G. Greig, and G. Poste. 1984. Experimental metastasis correlates with cyclic AMP accumulation in B16 melanoma clones. Nature (Lond.). 308:544-547.

26. Gehlsen, K. R. 1986. In vitro and in vivo study of melanoma tumor cell invasion and metastasis. Diss. Abstr. 47:1368. (Abstr.)

27. Bennett, D. C., T. J. Dexter, E. J. Ormerod, and I. R. Hart. 1986. Increased experimental metastatic capacity of a murine melanoma following induction of differentiation. Cancer Res. 46:32393244.

28. Preston, S. F., M. Volpi, C. M. Pearson, and R. D. Berlin. 1987. Regulation of cell shape in the Cloudman melanoma cell line. Proc. Natl. Acad. Sci. USA. 84:5247-5251.

29. Pawelek, J. M. 1976. Factors regulating growth and pigmentation of melanoma cells. J. Invest. Dermatol. 66:201-209.

30. Halaban, R., and A. B. Lerner. 1977. The dual effect of mela- nocyte-stimulating hormone (MSH) on the growth of cultured mouse melanoma cells. Exp. Cell Res. 108:111-117.

31. Abdel-Malek, Z., M. E. Hadley, M. D. Bregman, F. L. Meyskens, and V. J. Hruby. 1986. Actions of melanotropins on mouse melanoma cell growth in vitro. JNCI (J. Natl. Cancer Inst.). 76:857863.

32. Hart, I. R., J. Rao, and R. E. Wilson. 1989. cAMP induced c-fos expression in cells of melanocyte origin. Biochem. Biophys. Res. Commun. 150:408-413.

33. Kaur, J., P. Seligman, and W. Robinson. 1986. Effects of alpha melanocyte stimulating hormone (MSH) on human malignant melanoma. Proc. Annu. Mtg. Am. Soc. Clin. Oncol. 5:127. (Abstr.)

34. Herlyn, M., M. L. Mancianti, J. Jambrosic, J. B. Bolen, and H. Koprowski. 1988. Regulatory factors that determine growth and phenotype of normal human melanocytes. Exp. Cell Res. 179:322-331.

35. Smith, A. I., and J. W. Funder. 1988. Proopiomelanocortin processing in the pituitary, central nervous system, and peripheral tissues. Endocr. Rev. 9:159-179.

36. DeBold, C. R., J. K. Menefee, W. E. Nicholson, and D. N. Orth. 1989. Proopiomelanocortin gene is expressed in many normal human tissues and in tumors not associated with ectopic adrenocorticotropin syndrome. Mol. Endocrinol. 88:862-870.

37. Reichlin, S., and J. B. Martin. 1987. Regulation of adrenocorticotropic hormone (ACTH) secretion and its disorders. In Clinical Neuroendocrinology. S. Reichlin and J. B. Martin, editors. F. A. Davis Company, Philadelphia. 159-200.

38. Thody, A. J., C. Fisher, P. Kendal-Taylor, M. T. Jones, J. Price, and $R$. R. Abraham. 1985. The measurement and characterisation by high pressure liquid chromatography of immunoreactive alpha-melanocyte stimulating hormone in human plasma. Acta Endocrinol. 110:313-318.

39. Guerry, D., IV, M. A. Alexander, D. Elder, and M. F. Herlyn. 1987. Interferon-gamma regulates the $\mathrm{T}$ cell response to precursor nevi and biologically early melanoma. J. Immunol. 139:305-312.

40. Kameyama, K., S. Tanaka, Y. Ishida, and V. J. Hearing. 1989. Interferons modulate the expression of hormone receptors on the surface of murine melanoma cells. J. Clin. Invest. 83:213-221.

41. Lachman, L. B., C. A. Dinarello, N. D. Llansa, and I. J. Fidler. 1986. Natural and recombinant human interleukin 1-beta is cytotoxic for human melanoma cells. J. Immunol. 136:3098-3102.

42. Feng, J. D., T. Dao, and J. M. Lipton. 1987. Effects of preoptic microinjections of alpha-MSH on fever and normal temperature control in rabbits. Brain Res. Bull. 18:473-477.

43. Farrar, W. L., P. L. Killian, M. R. Ruff, J. M. Hill, and C. B. Pert. 1987. Visualization and characterization of interleukin 1 receptors in brain. J. Immunol. 139:459-463.

44. Sauder, D. N. 1985. Biologic properties of epidermal cell thymocyte-activating factor (ETAF). J. Invest. Dermatol. 85:176s-179s.

45. Swope, V. B., Z. A. Abdel-malek, D. N. Sauder, and J. J. Nordlund. 1989. A new role for epidermal cell-derived thymocyte activating factor/IL-1 as an antagonist for distinct epidermal cell function. J. Immunol. 142:1943-1949.

46. Greig, R. G., B. Lester, P. Sorensen, C. Buscarino, and G. Poste. 1985. Hormonal regulation of B16 melanoma metastasis. In Treatment of Metastasis: Problems and Prospects. K. Hellman and S. A. Eccles, editors. Taylor \& Francis, Philadelphia. 121-124. 